\title{
Physical Properties of Nanostructured CdO Films from Alkaline Baths Containing Saccharin as Additive
}

\author{
Bünyamin Şahin \\ Department of Physics, Faculty of Arts and Sciences, Mustafa Kemal University, 31034 Hatay, Turkey \\ Correspondence should be addressed to Bünyamin Şahin; sahin38@gmail.com
}

Received 11 April 2013; Accepted 22 May 2013

Academic Editors: L. De Stefano and Q. Fu

Copyright (C) 2013 Bünyamin Şahin. This is an open access article distributed under the Creative Commons Attribution License, which permits unrestricted use, distribution, and reproduction in any medium, provided the original work is properly cited.

\begin{abstract}
Nanostructured cadmium oxide $(\mathrm{CdO})$ films were fabricated on glass substrates from alkaline baths containing saccharin as an additive by a successive ionic layer adsorption and reaction (SILAR) method. The effects of saccharin concentration in the bath on the structural, morphological, and optical properties were studied by means of scanning electron microscopy (SEM), X-ray diffraction (XRD), photoluminescence, and Raman spectroscopy. The analyses showed that the surface morphologies, XRD peak intensities, Raman spectroscopy, and photoluminescence properties of $\mathrm{CdO}$ films changed with saccharin concentration. From the results, it can be said that morphological characteristic and optical properties of the films could be calibrated by adding various saccharin percentages in the growth bath.
\end{abstract}

\section{Introduction}

In recent years, transparent conductive oxide (TCO) layers have attracted much attention due to their high optical transmittance and low resistivity. They have been obtained by different research groups because they have potential applications in photovoltaic solar cells, phototransistors, liquid crystal displays, optical heaters, gas sensors, transparent electrodes, and other optoelectronic devices [1-3].

The optical, electrical, and morphological properties of the films could also be changed by using various additives in the growth solution. One of the methods is using some organic additives in the growth bath for solution-based synthesis. In general, additives are used in aqueous solution growth methods to control the surface morphology and the crystalline structure and to refine the grain size. The optical properties, such as the band gap energy, are quite dependent on the crystal sizes $[4,5]$. There are various additives such as saccharin, citric acid, and tartaric acid. The additives are especially used to control the surface morphology and to refine the grain size [6]. Saccharin is known to be used as a strong leveling agent for the surface and a grain refiner, by decreasing of the internal stresses in the deposits $[7,8]$.
Among the metal oxide semiconductors $\mathrm{CdO}$ is an $\mathrm{n}$ type semiconductor that crystallizes in the rock salt structure (fcc) and presents an optical band gap of about $2.2 \mathrm{eV}$ [9]. CdO has high electrical conductivity and optical transmittance in the visible region of the solar spectrum. Due to these properties of $\mathrm{CdO}$, it is one of the promising TCO from II to VI group of semiconductors. CdO films have been prepared so far by many different methods which are chemical bath deposition (CBD) [10], pulsed laser deposition [11], sol-gel [12], magnetron sputtering [13], metal-organic chemical vapor deposition [14], and successive ionic layer adsorption and reaction (SILAR) methods [15]. There have been practically no studies of saccharin addition process on the structural, morphological, and optical properties of nanostructured CdO films using the SILAR or other methods. In this study, for the first time, we report the effect of saccharin adding process on the structural, morphological, and optical properties of nanostructured $\mathrm{CdO}$ films.

The primary aim of this paper is to present the results of SEM, XRD, PL, and Raman analysis carried out for CdO films as a function of saccharin concentration. Structural properties as well as crystal quality were examined using XRD and Raman spectroscopy. Film morphology was studied 
with SEM micrographs. Optical properties of the films were investigated by the photoluminescence technique.

\section{Experimental Details}

In this work, we have investigated the effect of saccharin concentration during the growth of $\mathrm{CdO}$ films on glass substrates by the SILAR method. All the chemical reagents used in the experiments were analytical grade purchased from Sigma-Aldrich Company and Merck KGaA. The cleaning process of the substrates (microscope glass slides) consists of three steps which are cleaning in dilute sulfuric acid solution $\left(\mathrm{H}_{2} \mathrm{SO}_{4}: \mathrm{H}_{2} \mathrm{O}, 1: 5\right.$ by volume), in acetone, and in double distilled water for $5 \mathrm{~min}$, each in an ultrasonic bath [16]. Synthesis of the films was described as follows. $2.66 \mathrm{~g}$ cadmium acetate was weighted and mixed with $100 \mathrm{~mL}$ double distilled water $(18.2 \mathrm{M} \Omega \mathrm{cm})$ to obtain $0.1 \mathrm{M}$ cadmium acetate solution. Then, the solution was stirred in a magnetic stirrer at room temperature in order to get a transparent and well-dissolved solution. After stirring, the $\mathrm{pH}$ value of the solution was increased to $\approx 12.0$ by adding ammonia $\left(\mathrm{NH}_{3}\right)$. The solution was heated to about $85^{\circ} \mathrm{C}$. The substrates were dipped into the solution and kept for $30 \mathrm{~s}$. Then, they were dipped into hot water $\left(85^{\circ} \mathrm{C}\right)$ for $30 \mathrm{~s}$. This cycle was applied for 20 times. To investigate the effects of saccharin concentration to the films, five series of samples were produced. The bath for the first one was pure (i.e., contains only cadmium acetate, water and ammonia), the other baths contain $1,3,6$, and $12 \%$ saccharin, respectively. After the film growth process, $\mathrm{Cd}(\mathrm{OH})_{2}$ films were annealed at $450^{\circ} \mathrm{C}$ for $1 \mathrm{~h}$ in a Protherm PTF $12 / 50 / 450$ tube furnace air atmosphere in order to convert $\mathrm{Cd}(\mathrm{OH})_{2}$ into $\mathrm{CdO}$.

\section{Results and Discussion}

3.1. Morphological Studies. The morphology and microstructure of $\mathrm{CdO}$ products were examined by SEM. In order to investigate the effect of the saccharin percentage, we have conducted the experiments at five different percentages. Figure 1 shows the structures of $\mathrm{CdO}$ nanoparticles which were grown in pure and saccharin added baths on the glass substrates. It can be seen that all the substrates were fully covered by $\mathrm{CdO}$ nanoparticles. The addition of saccharin affected the morphology on a macrovision, that is, the films seemed to be more porous with some voids. All images show homogenous and dense surfaces. The surface morphology and grain sizes of $\mathrm{CdO}$ films were changed considerably as a function of saccharin concentration. By using a pixels analysis program, the diameters of the grains were found as about $1730,1390,1510,1471$, and $1720 \mathrm{~nm}$ for pure and $1,3,6$, and $12 \%$ for saccharin added samples, respectively. These SEM images show that surface morphology and grain size of the films could be controlled by saccharin percentage.

3.2. X-Ray Diffraction. The structural properties of the pure and saccharin added CdO films were determined by XRD measurements. X-Ray diffraction analyses of the films were depicted in Figure 2. It shows typical XRD patterns of
TABLE 1: Peak intensities and average grain size values of CdO films as a function of saccharin concentration.

\begin{tabular}{lccc}
\hline $\begin{array}{l}\text { Saccharin } \\
\text { concentration }\end{array}$ & \multicolumn{2}{c}{ Relative peak intensity } & Average grain Size (nm) \\
\hline $0 \%$ & 6937 & $(200)$ & 1730 \\
$1 \%$ & 15460 & 11902 & 1390 \\
$3 \%$ & 12983 & 9794 & 1510 \\
$6 \%$ & 13784 & 10395 & 1571 \\
$12 \%$ & 6500 & 4796 & 1720 \\
\hline
\end{tabular}

the films that have different saccharin concentration percentages in the growth solution. All diffraction peaks indicate the polycrystalline nature of $\mathrm{CdO}$ compound with cubic $\mathrm{NaCl}$ structure (JCPDS card number: $05-0640$ for $\mathrm{CdO}$ ). The intensities of (111), (200), (220), (311), and (222) and peaks in the 1,3 , and $6 \%$ saccharin added films were found to be slightly increased as seen in Figure 2 and decreased at 12\% saccharin concentration. The relative peak intensities of the films are listed in Table 1. The surface morphology and grain size of CdO films were changed considerably as a function of saccharin concentration which is in agreement with the studies [7, 17-19]. Therefore, although the films' conditions are kept unchanged, the crystallinity and surface morphology change with saccharin concentration [20].

3.3. Photoluminescence Properties. Room temperature photoluminescence spectra of $\mathrm{CdO}$ films measured in the visible region are shown in Figure 3. The analyses of PL spectroscopy at room temperature display various peaks. PL intensity around $540 \mathrm{~nm}$ which corresponds to the orange region of the electromagnetic spectrum changes with increasing saccharin concentration. The intense emission around 540, 550 , and $565 \mathrm{~nm}$ might be attributed to the combination of the electrons from the conduction band and holes from the valence band [21]. The PL measurements show that the pure $\mathrm{CdO}$ film has weak luminescence behavior, but it can interact with other materials to realize its applications in luminescent devices. Actually, this fact is not valid for nanoparticles [22]. As the saccharin concentration increases, the intensity of peak emission also increases. As a result, the number of defect sites decreased with increasing saccharin concentration which is approved by the PL signals. Also, the band structure changes due to the change in the concentration of saccharin. As seen in Figure 3, the shifting in the optical band gap of CdO films can be explained by the saccharin rate which may be attributed to change in grain size [23-25]. There have been suggestions that a distribution of grain sizes may be responsible for this $[26,27]$.

3.4. Raman Properties. The assignment of Raman mode of $\mathrm{CdO}$ is very difficult, and it is known mostly that $\mathrm{CdO}$ is Raman inactive [28]. In spite of the technological importance of CdO films, the Raman properties of this material have not been further investigated. The Raman spectrum of the pure and $1,3,6$, and $12 \%$ saccharin added CdO films in the $120-1500 \mathrm{~cm}^{-1}$ region was recorded by SENTERRA which is 


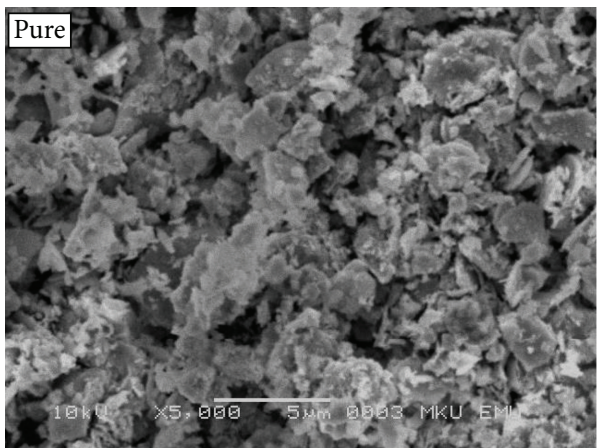

(a)

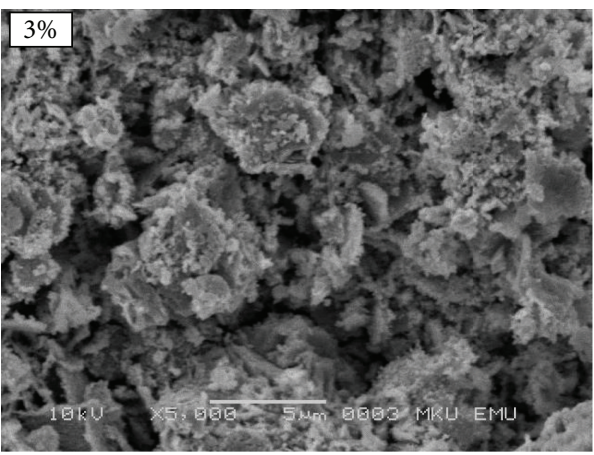

(c)

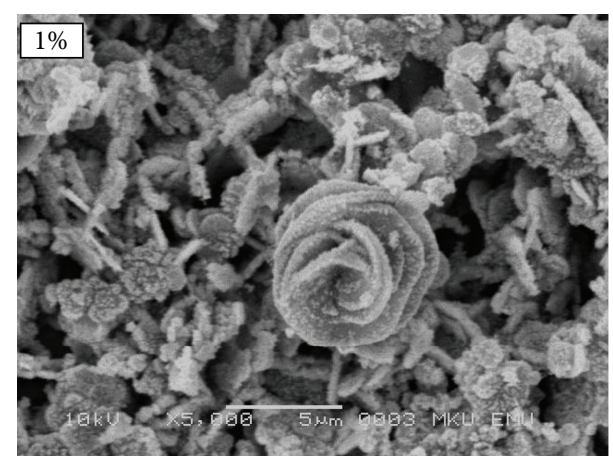

(b)

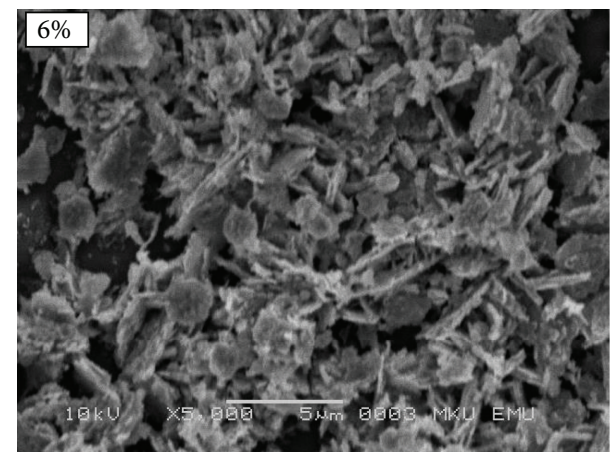

(d)

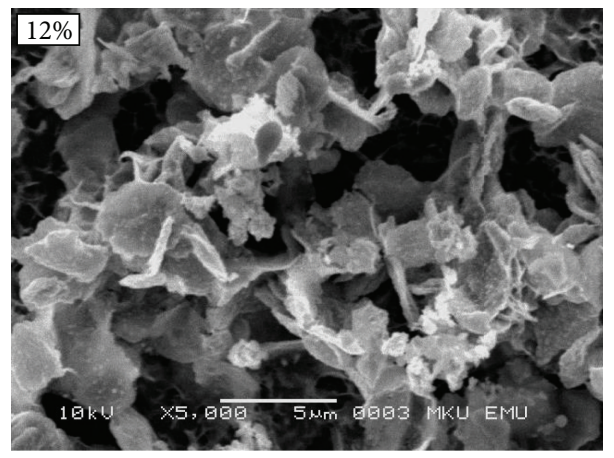

(e)

FIGURE 1: SEM images of CdO thin films prepared in the solutions having the saccharin concentrations of 0 (pure), $1,3,6$, and $12 \%$.

a high performance Raman microscope spectrometer using a $532 \mathrm{~nm}$ diode lasers.

Figure 4 shows the Raman spectra of $\mathrm{CdO}$ films at room temperature as a function of saccharin concentrations. $\mathrm{CdO}$ films revealed three distinct peaks. First sharp peak appears at $300 \mathrm{~cm}^{-1}$ which is not existent in pure CdO film, but when saccharin is added, it started to be observed. The peak position changed much with the saccharin concentration. The area under the Raman peak changed with the saccharin percentage and increased with higher concentration, probably due to saccharin induced surface roughness [29]. The second peak appears at $590 \mathrm{~cm}^{-1}$. The peak intensity and the area under the Raman peak decreased with the increase of saccharin concentration, The third peak appears at around $1100 \mathrm{~cm}^{-1}$. The intensity of the peak decreased with increasing saccharin concentration. As the saccharin concentration increases, the intensity of the peak around $300 \mathrm{~cm}^{-1}$ becames stronger, while the peak at $1100 \mathrm{~cm}^{-1}$ disappeared, indicating a complete phase transition. Phase transitions observed in the Raman spectra are in complete agreement with our XRD results.

\section{Conclusion}

In this study, $\mathrm{CdO}$ nanostructures were produced by the SILAR method. The structural, morphological, and optical properties of $\mathrm{CdO}$ films were investigated. The $\mathrm{CdO}$ films are found as polycrystalline with cubic structure. We used SEM, XRD, PL, and Raman scattering spectroscopy to determine morphology, grain size, crystallinity, and optical properties of CdO films. This may be crucial for technological device applications. The results can be concluded as follows. 


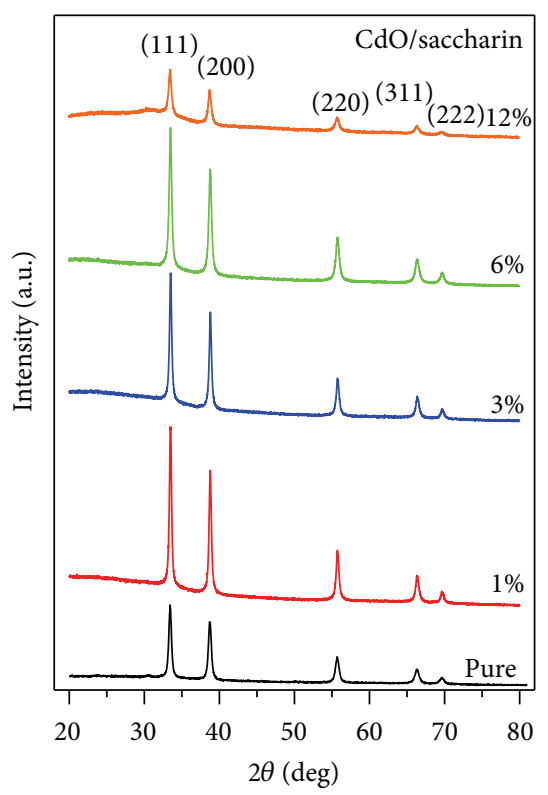

FIGURE 2: XRD patterns of CdO films as a function of saccharin concentration.

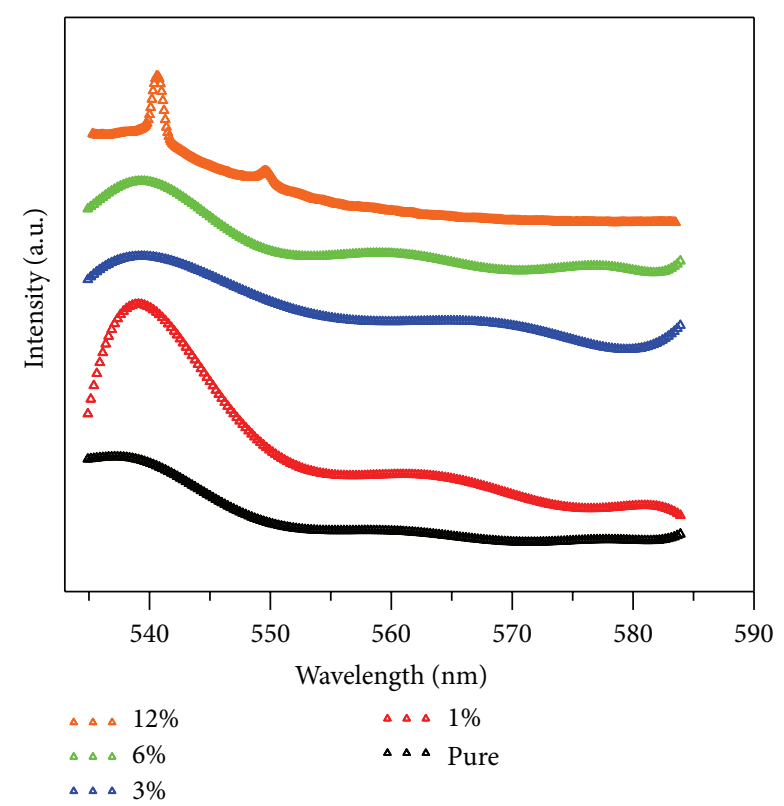

Figure 3: PL spectra of CdO films at room temperature as a function of saccharin concentration.

(i) Saccharin addition affected the morphology on a macrovision. The films seem to be more porous with some voids, and all images show homogenous and dense surfaces. The surface morphology and grain sizes of CdO films were changed considerably as a function of saccharin concentration.

(ii) Saccharin addition up to $6 \%$ to the bath causes an increase in the intensities of (111) and (200) peaks but causes a decrease at $12 \%$ concentration levels. It is observed from the SEM images and XRD patterns

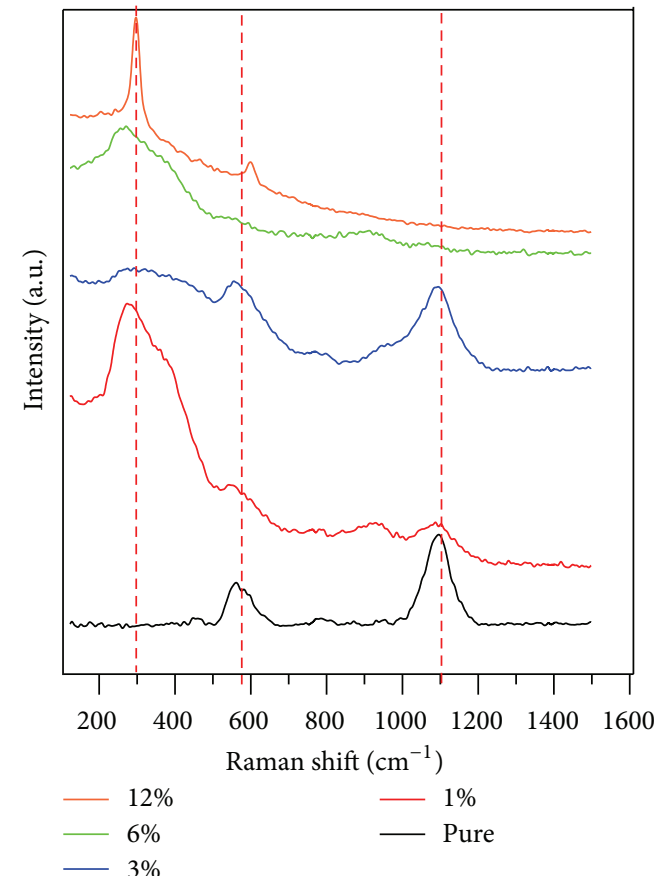

FIgURE 4: Raman spectra of CdO films at room temperature as a function of saccharin concentration.

that the crystallite and grain sizes of the structures changed with saccharin addition.

(iii) The PL measurement showed that the pure CdO film has weak luminescence behavior, but it can interact with other materials to realize its applications in luminescent devices.

(iv) Saccharin added CdO films revealed three distinct Raman peaks. With the change of saccharin concentration, the intensity and the area under the Raman peaks were changed.

As a result, structural, morphological, optical, and spectroscopical characteristic, of nanostructured $\mathrm{CdO}$ films could be calibrated by various saccharin percentages. Thus, the nanostructured $\mathrm{CdO}$ materials would be hopeful for various advanced device technology.

\section{References}

[1] M. Ali Yıldırım and A. Ates, "Structural, optical and electrical properties of $\mathrm{CdO} / \mathrm{Cd}(\mathrm{OH})_{2}$ thin films grown by the SILAR method," Sensors and Actuators A, vol. 155, pp. 272-277, 2009.

[2] B. J. Zheng, J. S. Lian, L. Zhao, and Q. Jiang, "Optical and electrical properties of In-doped CdO thin films fabricated by pulse laser deposition," Applied Surface Science, vol. 256, no. 9, pp. 2910-2914, 2010.

[3] A. A. Dakhel, "Optoelectronic properties of Eu- and H-codoped CdO films," Current Applied Physics, vol. 11, no. 1, pp. 11-15, 2011.

[4] H. M. Cakmak, H. A. Cetinkara, S. Kahraman et al., "Effects of thermal oxidation temperature on vacuum evaporated tin dioxide film," Superlattices and Microstructures, vol. 51, no. 3, pp. 421-429, 2012. 
[5] S. Aksoy, Y. Caglar, S. Ilican, and M. Caglar, "Effect of heat treatment on physical properties of CdO films deposited by solgel method," International Journal of Hydrogen Energy, vol. 34, no. 12, pp. 5191-5195, 2009.

[6] M. H. Gharahcheshmeh and M. H. Sohi, "Study of the corrosion behavior of zinc and $\mathrm{Zn}$-Co alloy electrodeposits obtained from alkaline bath using direct current," Materials Chemistry and Physics, vol. 117, no. 2-3, pp. 414-421, 2009.

[7] S.-H. Kim, H.-J. Sohn, Y.-C. Joo et al., "Effect of saccharin addition on the microstructure of electrodeposited Fe-36 wt.\% Ni alloy," Surface and Coatings Technology, vol. 199, no. 1, pp. 4348, 2005.

[8] A. M. Rashidi and A. Amadeh, "The effect of saccharin addition and bath temperature on the grain size of nanocrystalline nickel coatings," Surface and Coatings Technology, vol. 204, no. 3, pp. 353-358, 2009.

[9] M. Ortega, G. Santana, and A. Morales-Acevedo, "Optoelectronic properties of $\mathrm{CdO} / \mathrm{Si}$ photodetectors," Solid-State Electronics, vol. 44, no. 10, pp. 1765-1769, 2000.

[10] L. R. de León-Gutiérrez, J. J. Cayente-Romero, J. M. Peza-Tapia, E. Barrera-Calva, J. C. Martínez-Flores, and M. Ortega-López, "Some physical properties of Sn-doped CdO thin films prepared by chemical bath deposition," Materials Letters, vol. 60, no. 2930, pp. 3866-3870, 2006.

[11] M. Yan, M. Lane, C. R. Kannewurf, and R. P. H. Chang, "Highly conductive epitaxial Cdo thin films prepared by pulsed laser deposition," Applied Physics Letters, vol. 78, no. 16, pp. 23422344, 2001.

[12] J. S. Cruz, G. T. Delgado, R. C. Perez et al., "Dependence of electrical and optical properties of sol-gel prepared undoped cadmium oxide thin films on annealing temperature," Thin Solid Films, vol. 493, no. 1-2, pp. 83-87, 2005.

[13] T. K. Subramanyam, S. Uthanna, and B. S. Naidu, "Preparation and characterization of $\mathrm{CdO}$ films deposited by dc magnetron reactive sputtering," Materials Letters, vol. 35, no. 3-4, pp. 214220, 1998.

[14] X. Liu, C. Li, S. Han, J. Han, and C. Zhou, "Synthesis and electronic transport studies of CdO nanoneedles," Applied Physics Letters, vol. 82, no. 12, pp. 1950-1952, 2003.

[15] R. R. Salunkhe and C. D. Lokhande, "Effect of film thickness on liquefied petroleum gas (LPG) sensing properties of SILAR deposited CdO thin films," Sensors and Actuators B, vol. 129, no. 1, pp. 345-351, 2008.

[16] F. Bayansal, S. Kahraman, G. Ankaya, H. A. Etinkara, H. S. Guder, and H. M. Akmak, "Growth of homogenous $\mathrm{CuO}$ nanostructured thin films by a simple solution method," Journal of Alloys and Compounds, vol. 509, no. 5, pp. 2094-2098, 2011.

[17] R. J. Deokate, S. M. Pawar, A. V. Moholkar et al., "Spray deposition of highly transparent fluorine doped cadmium oxide thin films," Applied Surface Science, vol. 254, no. 7, pp. 2187-2195, 2008.

[18] M. Ahmad, C. Pan, W. Yan, and J. Zhu, "Effect of Pbdoping on the morphology, structural and optical properties of $\mathrm{ZnO}$ nanowires synthesized via modified thermal evaporation," Materials Science and Engineering B, vol. 174, no. 1-3, pp. 55-58, 2010.

[19] S. H. Mosavat, M. E. Bahrololoom, and M. H. Shariat, "Electrodeposition of nanocrystalline $\mathrm{Zn}-\mathrm{Ni}$ alloy from alkaline glycinate bath containing saccharin as additive," Applied Surface Science, vol. 257, no. 20, pp. 8311-8316, 2011.

[20] K. C. Preetha, K. V. Murali, A. J. Ragina, K. Deepa, and T. L. Remadevi, "Effect of cationic precursor $\mathrm{pH}$ on optical and transport properties of SILAR deposited nano crystalline $\mathrm{PbS}$ thin films," Current Applied Physics, vol. 12, no. 1, pp. 53-59, 2012.

[21] M. Benhaliliba, C. E. Benouis, A. Tiburcio-Silver et al., "Luminescence and physical properties of copper doped CdO derived nanostructures," Journal of Luminescence, vol. 132, pp. 26532658, 2012.

[22] M. A. Flores-Mendoza, R. Castanedo-Perez, G. Torres-Delgado, S. A. Toms, J. G. Mendoza-Alvarez, and O. Zelaya-Angel, "Lowtemperature photoluminescence spectra of $\mathrm{CdOIn}_{2} \mathrm{O}_{3}$ thin films prepared by solgel," Journal of Luminescence, vol. 130, no. 12, pp. 2500-2504, 2010.

[23] V. R. Shinde, C. D. Lokhande, R. S. Mane, and S. Han, "Hydrophobic and textured $\mathrm{ZnO}$ films deposited by chemical bath deposition: annealing effect," Applied Surface Science, vol. 245, no. 1-4, pp. 407-413, 2005.

[24] Y. Zhang, W. Fa, F. Yang, Z. Zheng, and P. Zhang, "Effect of annealing temperature on the structural and optical properties of $\mathrm{ZnO}$ thin films prepared by sol-gel method," Ionics, vol. 16, no. 9, pp. 815-820, 2010.

[25] F. Yakuphanoglu, "Synthesis and electro-optic properties of nanosized-boron doped cadmium oxide thin films for solar cell applications," Solar Energy, vol. 85, no. 11, pp. 2704-2709, 2011.

[26] P. F. Trwoga, A. J. Kenyon, and C. W. Pitt, "Modeling the contribution of quantum confinement to luminescence from silicon nanoclusters," Journal of Applied Physics, vol. 83, no. 7, pp. 37893794, 1998.

[27] H. Yorikawa and S. Muramatsu, "Logarithmic normal distribution of particle size from a luminescence line-shape analysis in porous silicon," Applied Physics Letters, vol. 71, no. 5, pp. 644646, 1997.

[28] Z. V. Popovic, G. Stanisic, D. stojanovic, and R. Kostic, "Infrared and raman spectra of CdO," Physica Status Solidi B, vol. 165, pp. 109-112, 1991.

[29] K. Senthil, D. Mangalaraj, S. K. Narayandass, R. Kesavamoorthy, and G. L. N. Reddy, "Raman scattering and XRD analysis in argon ion implanted CdS thin films prepared by vacuum evaporation," Nuclear Instruments and Methods in Physics Research $B$, vol. 173, no. 4, pp. 475-482, 2001. 

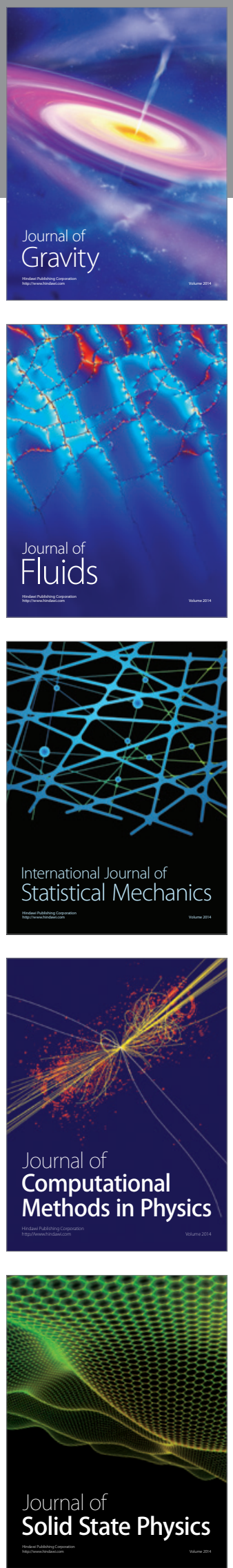

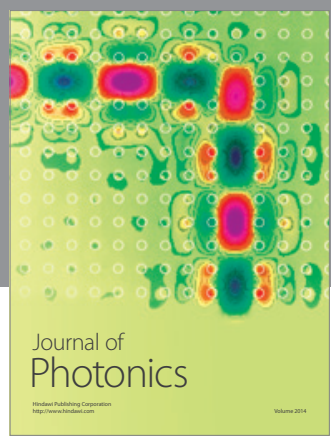

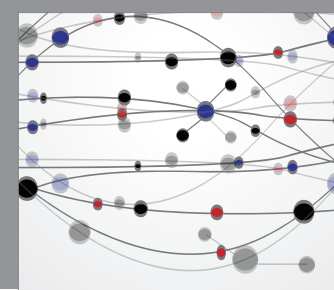

The Scientific World Journal

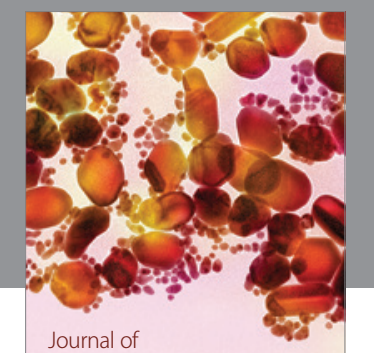

Soft Matter
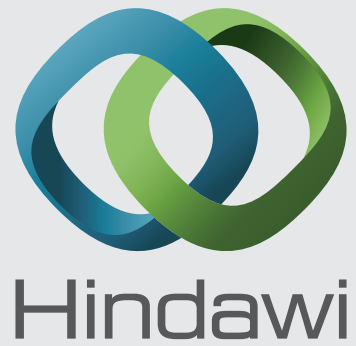

Submit your manuscripts at

http://www.hindawi.com
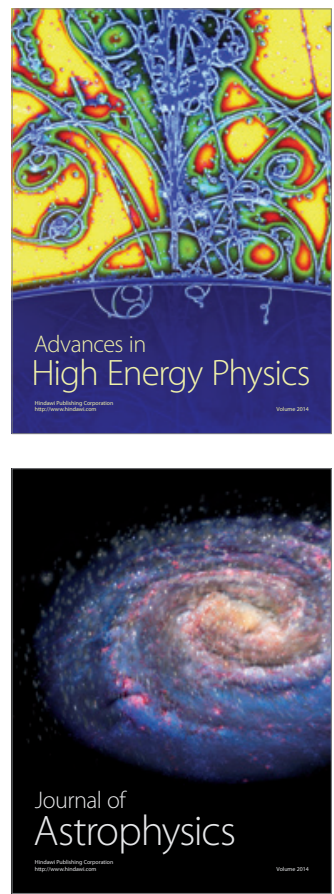
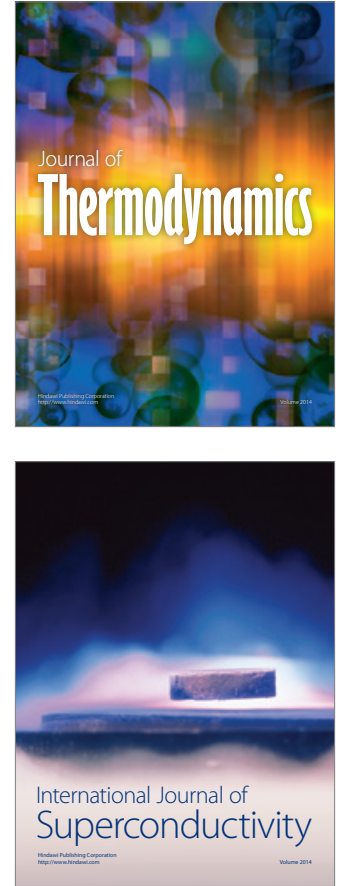
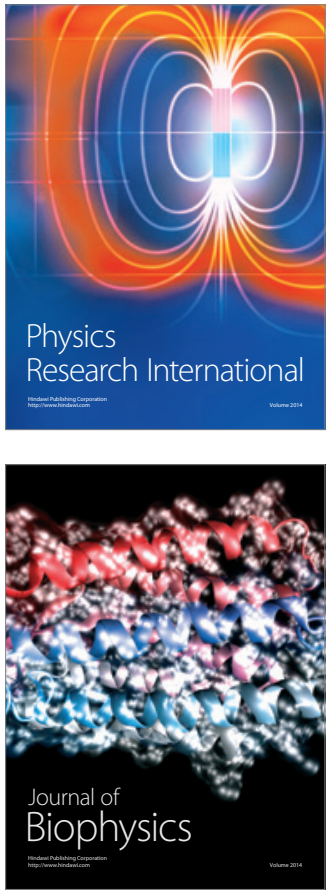
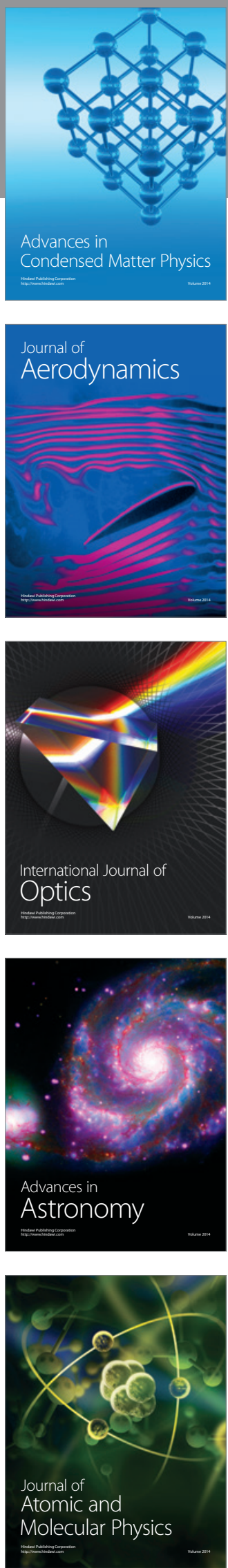